\title{
Apples to oranges: Making sense of hybrid palliation for hypoplastic left heart syndrome
}

Travis J. Wilder, MD, and Christopher A. Caldarone, MD

Feature Editor's Introduction-Hypoplastic left heart syndrome (HLHS) remains one of the most challenging anomalies for the surgical repertoire. Despite initial nearly overwhelming enthusiasm for a hybrid strategy as the first surgical step in single-ventricle palliation, the hybrid procedure did not show convincing superiority over conventional stage 1 surgical palliation. Here, experts discuss the role, pitfalls, potential benefits, and outcomes of the hybrid procedure.

\section{Igor E. Konstantinov, MD, PhD, FRACS}

In the early 1980s, the Norwood operation revolutionized treatment for children with hypoplastic left heart syndrome (HLHS) and related variants. ${ }^{1}$ Although survival among children with HLHS has continued to improve, outcomes for patients with HLHS remain comparatively poor compared with outcomes in patients with less severe congenital heart defects. ${ }^{2}$ In the early 1990s, the hybrid strategy for single-ventricle palliation was developed as an alternative management approach, initially aimed at improving outcomes among neonates with HLHS by providing a bridge to heart transplantation. ${ }^{3}$ Hybrid strategies subsequently became a stage 1 alternative with the objective of achieving Fontan completion. Enthusiasm for hybrid strategies was based on the expectation that avoiding cardiopulmonary bypass (CPB) and deep hypothermic circulatory arrest (DHCA) or antegrade cerebral perfusion (ACP) during the neonatal period would provide superior long-term outcomes.

The objectives of any stage 1 palliation strategy for neonates with HLHS are to achieve (1) unobstructed systemic outflow, (2) balanced pulmonary blood flow (PBF), (3) unrestricted pulmonary venous egress, and (4) unobstructed coronary artery perfusion. ${ }^{4}$ The hybrid stage 1 procedure as initially described achieved these objectives via

From the Division of Congenital Heart Surgery, Texas Children's Hospital, Baylor College of Medicine, Houston, Tex.

Received for publication Sept 25, 2020; accepted for publication Oct 6, 2020; available ahead of print Nov 14, 2020.

Address for reprints: Travis J. Wilder, MD, Legacy Tower, Floor 19, 6651 Main St, Mail Code 19345H, Houston, TX 77030 (E-mail: tjwilder@texaschildrens.org). JTCVS Open 2020;4:47-54

2666-2736

Copyright (C) 2020 The Authors. Published by Elsevier Inc. on behalf of The American Association for Thoracic Surgery. This is an open access article under the CC BY-NCND license (http://creativecommons.org/licenses/by-nc-nd/4.0/).

https://doi.org/10.1016/j.xjon.2020.10.002

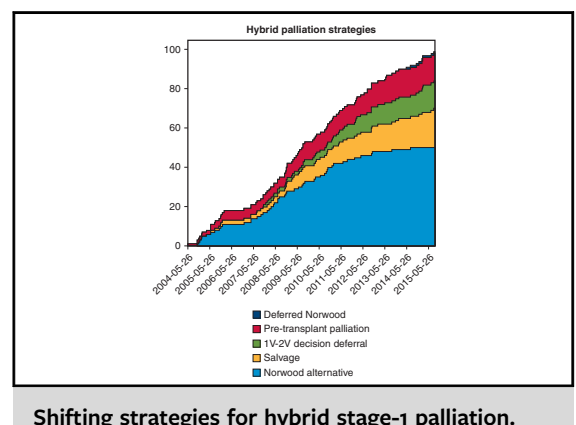

Shifting strategies for hybrid stage-1 palliation.

CENTRAL MESSAGE

Hybrid palliation is a niche treatment strategy for neonates with hypoplastic left heart syndrome. Uniform terminology for intent and risk stratification will help compare outcomes, leading to improved clinical decision making.

See Commentaries on pages 55 and 56.

catheter-based stenting of the patent ductus arteriosus (PDA) combined with surgically placed bilateral pulmonary artery (PA) bands and, if needed, balloon atrial septostomy. ${ }^{3,5,6}$ In the "conventional" hybrid approach, a comprehensive stage 2 (CS2) operation is performed 4 to 6 months after hybrid stage 1 palliation. The CS2 operation consists of PA band and ductal stent removal, atrial septectomy, aortic arch reconstruction, and creation of a bidirectional superior cavopulmonary connection (SCPC). ${ }^{7}$ The objective following second-stage palliation, either Norwood or hybrid, is for children to undergo Fontan palliation (total cavopulmonary connection) at around 3 years of age.

Since the introduction of hybrid strategies in the early 1990s, variations of the conventional technique involving surgical PA banding and ductal stent placement have emerged. ${ }^{3}$ Innovative strategies for hybrid palliation have evolved for application in a number of clinical scenarios. Unfortunately, however, as palliative strategies and technical details associated with the hybrid procedure have 
evolved, the intention of the clinicians using the hybrid approach is not always clearly articulated. For example, clinical intent might be to palliate for planned cardiac transplantation, salvage for a patient who presents with shock or organ dysfunction, or as an intentional alternative to the Norwood procedure because of patient/family preference. Consequently, a retrospective analysis of hybrid strategy outcomes is challenging.

Standardized definitions of palliative intent and details of the variations in procedural techniques are important to permit risk stratification and comparison of outcomes between the hybrid and Norwood strategies and permit comparisons across institutions. In this review, we summarize the contemporary hybrid strategy literature, emphasizing patterns of hybrid use, in an effort to promote clarification and standardization of terms of clinical intention and thereby allow more refined assessment of outcomes.

\section{SURGICAL CONSIDERATIONS WITH HYBRID SINGLE-VENTRICLE PALLIATION}

Although hybrid palliation offers several theoretical advantages compared with the Norwood strategy, understanding outcomes and potential limitations of the hybrid strategy is important to identify the optimal clinical scenario for hybrid strategies.

\section{Hybrid Palliation: Stages I and II}

Overall survival for patients after hybrid palliation has been studied independently as well as in comparison to recipients of a Norwood procedure. Although reports evaluating outcomes after hybrid palliation are often confounded by biased patient selection or heterogeneous patient populations, in the aggregate, overall survival is similar after the hybrid and Norwood stage 1 procedures. $^{7-11}$ An important difference between hybrid and Norwood stage 1 palliation strategies is the complexity of the second-stage operation. That is, the CS2 operation is more complex than the typical SCPC after Norwood procedures. Importantly, aortic arch reconstruction during the CS2 requires either DHCA or ACP and their attendant risks. The relative complexity of the CS2 operation after hybrid stage 1 is considered a potential limitation of hybrid strategies. As such, evaluating outcomes after the CS2 is important.

Compared with the stage 2 SCPC after a Norwood operation, which does not require cardiac arrest in most situations, the CS2 after a hybrid procedure is associated with worse outcomes. ${ }^{12,13}$ However, centers experienced with hybrid palliation are able to achieve mortality rates of 5\% to $7 \%$ after $\mathrm{CS} 2 .^{7,11}$ Despite these favorable results, the hospital mortality associated with the CS2 operation remains higher than that with the SCPC after the Norwood procedure. ${ }^{11,14}$ A recent review of the Society of Thoracic Surgeons (STS) Congenital Heart Surgery Database reported a $12.4 \%$ operative mortality after $\mathrm{CS} 2,{ }^{12}$ considerably higher than the STS-reported hospital mortality of $2.5 \%$ for SCPC. ${ }^{13}$

\section{PA Intervention}

PA reintervention, particularly on the left PA (LPA), is an important consideration after either hybrid or Norwood stage-1 palliation. ${ }^{15-18}$ Repeated PA intervention may negatively impact PA growth, which is a critical factor in determining Fontan candidacy and post-Fontan outcomes. PA interventions before stage 2 are uncommon for both hybrid and Norwood strategies. ${ }^{17}$ However, patients undergoing hybrid palliation are at increased risk for PA reintervention compared with patients undergoing Norwood procedures. ${ }^{16,17,19}$

PA reintervention rates after CS2 range between $46 \%{ }^{11}$ and $50 \%{ }^{17}$ at experienced hybrid centers but can be as high as $86 \%$ in low-volume centers. ${ }^{20}$ Most PA reinterventions are directed at the LPA and include catheter-based balloon dilation with or without PA stent placement. ${ }^{11,15,17,18}$ PA size at the time of Fontan palliation is smaller following hybrid stage 1 than after a Norwood procedure. ${ }^{15,17,19}$ Even though hybrid palliation is associated with increased rates of PA reintervention, in high-volume centers, PA reinterventions did not impact survival or Fontan candidacy. ${ }^{17,18}$

In aggregate, the data on the fate of PA growth after stage 1 palliation suggest that PA stenosis occurs more frequently following hybrid palliation than after Norwood palliation, occurs most commonly after stage 2 , and usually involves the LPA. Importantly, PA stenosis is largely treatable and does not seem to have a lasting impact on survival, Fontan completion, or successful palliation.

\section{Postoperative Hemodynamics and Coronary Artery Perfusion}

Although the objectives for stage 1 palliation can be achieved with both the hybrid approach and the Norwood procedure, there are important differences in cardiovascular physiology between the 2 strategies.

Retrograde arch obstruction. Following a Norwood procedure, systemic arterial blood flow-including cerebral and coronary circulation-is delivered via the reconstructed neoaorta. In contrast, circulation after hybrid palliation relies on retrograde arch perfusion of the brachiocephalic and coronary arteries. Consequently, arch obstruction secondary to narrowing of the isthmus by the ductal stent or delayed coarctation can result in cerebral and coronary malperfusion. ${ }^{21,22}$ Risk factors for retrograde arch obstruction include aortic atresia, small aortic root, increased angle between the ductus arteriosus and aortic isthmus, and increased peak Doppler velocities in the retrograde arch. ${ }^{23}$

For patients at risk of retrograde arch obstruction, a prophylactic main PA-to-innominate artery (reverse modified 
Blalock-Taussig [BT]) shunt may help mitigate the effects of retrograde arch obstruction. ${ }^{24}$ Although the Toronto group demonstrated the feasibility of using a reverse BT shunt ${ }^{25}$ current data supporting use of a reverse BT shunt are limited. Placement of an aortic isthmus stent is an alternative strategy to secure retrograde arch perfusion in patients with obstruction due to "jailing" of the isthmus from the ductal stent. ${ }^{23}$ However, more common strategies to avoid ductal stenting (and potential retrograde arch obstruction) among high-risk neonates for retrograde arch obstruction include the use of continuous prostaglandin infusion to maintain the ductal patency and avoidance of ductal stenting or abandonment of the hybrid strategy with a Norwood procedure. ${ }^{26}$

Diastolic runoff. Diastolic runoff occurs when blood is shunted away from the systemic and coronary arterial systems in favor of the pulmonary circulation. A potential consequence of diastolic runoff is poor coronary perfusion or "coronary steal," which in severe cases causes decreased myocardial reserve and hemodynamic compromise. The arterial source of PBF makes the physiology after Norwood-BT and hybrid stage 1 susceptible to diastolic runoff, which can lead to hemodynamic instability in the early postoperative period. ${ }^{4,27-30}$

Inconsistent hemodynamics. Creating bilateral PA bands that precisely balance systemic and PA blood flow while also allowing for equal distribution of blood flow to each lung is technically challenging. Although there are various physiological parameters to help guide PA band placement, this is an inexact process. In addition, the early period after hybrid stage 1 tends to be associated with increased systemic vascular resistance, decreased cardiac efficiency, and lower cardiac output compared with the Norwood procedure, ${ }^{9,31}$ with higher oxygen extraction ratios despite lower oxygen consumption. ${ }^{31}$ Typically, the hemodynamic discrepancy between patients undergoing a Norwood procedure and those undergoing a hybrid procedure resolves within 48 hours. During this period, strategies to reduce afterload help improve cardiac efficiency, especially in those neonates with marginal myocardial reserve. ${ }^{31}$

\section{Neurodevelopment}

For neonates with HLHS, brain development is delayed by an average of 5 weeks at birth compared with normal controls. ${ }^{32,33}$ Not surprisingly, immature brain development increases the risk for compromised neurodevelopment when exposed to $\mathrm{CPB} .{ }^{34,35}$ Early adoption of hybrid procedures was driven by the presumed benefit of avoiding CPB and arch reconstruction in the neonate; however, skeptics argue that important physiological considerations regarding persistent retrograde aortic arch perfusion diminish the benefits gained by avoiding neonatal CPB. ${ }^{19,36}$

A recent study evaluating brain magnetic resonance imaging results in children age 2 to 3 years found that patients who underwent hybrid palliation had comparable total gray matter as age-matched controls, but children who underwent Norwood palliation had persistent gray matter loss. ${ }^{37}$ The clinical significance of reduced brain volume on functional neurologic outcomes is unknown, however. Furthermore, these findings are confounded by results showing no difference in neurocognitive outcomes among toddlers who underwent hybrid or Norwood palliation when assessed by the Bayley-III standardized neuromotor examination. ${ }^{38}$

Although it is a logical hypothesis to assume that delaying DHCA or ACP from the neonatal period to the timing of CS2 ultimately leads to improved cognitive development, the available data supporting or refuting the neurologic benefit of hybrid strategies are inconclusive.

\section{Current Strategies for Hybrid Palliation}

Today, only a handful of centers report using hybrid strategies as a primary approach for stage 1 palliation $^{7,11,17,39,40}$; however, many centers have adopted "nontraditional" hybrid strategies for specialized clinical circumstances (Figure 1). ${ }^{15,41-44}$ Although there is no formal consensus, we propose that current hybrid approaches can be classified in to 5 categories:

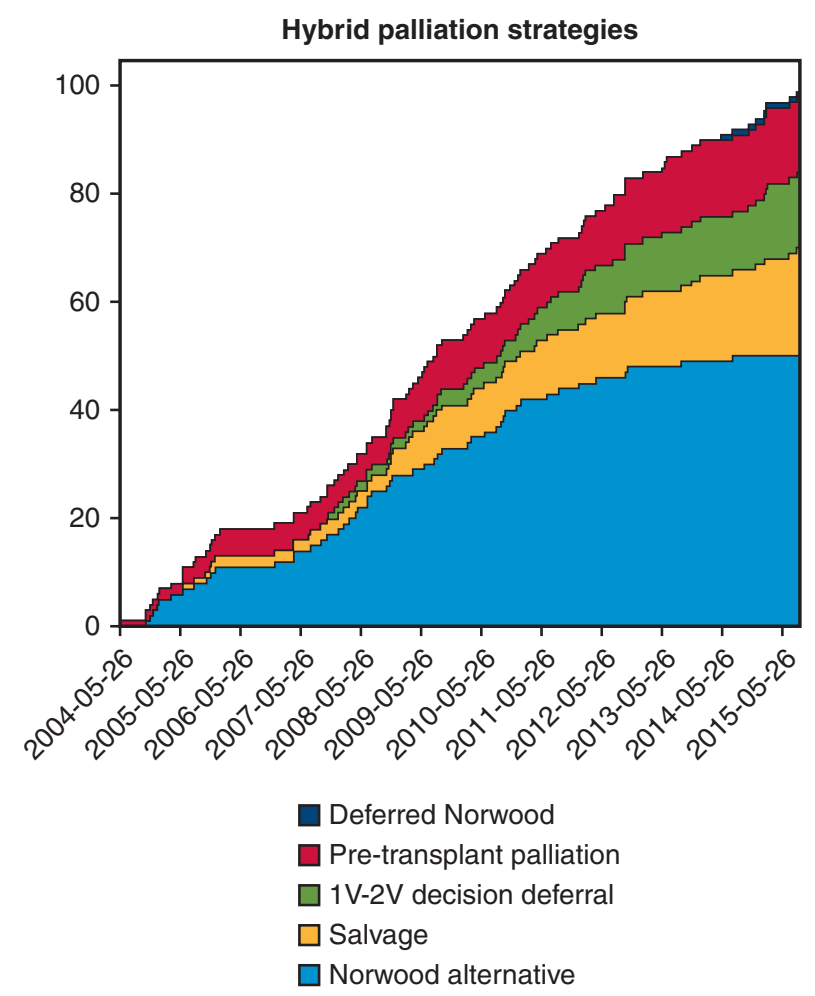

FIGURE 1. Shifting palliation strategies. Cumulative sum plot indicating the pattern of hybrid use over an 11-year period at the Hospital for Sick Children based on palliation strategy (ie, indication). In recent years, there is a decreased trend toward the use of hybrid as a Norwood alternative, whereas deferred Norwood and univentricular-biventricular decision deferral strategies have increased. $1-V$, Univentricular; $2-V$, biventricular. 
- Norwood alternative: conventional hybrid palliation with a stage 1 procedure which includes bilateral PA banding and maintenance of ductal patency with a PDA stent in patients who otherwise might be suitable for a Norwood procedure with CS2 as the second planned procedure.

- Salvage procedure: bilateral PA banding to stabilize patients who are not considered suitable candidates for the Norwood operation owing to hemodynamic instability. After stabilization, the patients might undergo a delayed Norwood procedure, CS2, or transplantation.

- Deferred Norwood strategy: use of the hybrid approach to defer a planned Norwood operation from the neonatal period, commonly using continuous prostaglandin infusion to maintain ductal patency.

- Pretransplantation palliation: use of the hybrid approach to stabilize hemodynamics and control PBF and thereby minimize waiting list attrition in a patient listed for cardiac transplantation.

- Univentricular-biventricular decision deferral: stabilization of hemodynamics and control of PBF in a patient with borderline left heart structures in whom feasibility for biventricular repair is uncertain in the neonatal period, with consideration for maintenance of a restrictive atrial septum (Table 1$)^{41}$

Creating a standard language with respect to palliative intent and risk stratification is necessary to accurately assess hybrid outcomes. That is, to compare "apples to apples" and thus determine the ideal setting for hybrid stage 1 use, a clear understanding of hybrid intent and patient characteristics is necessary.

\section{Norwood Alternative}

In the strictest sense, the use of hybrid strategies as a "Norwood alternative" extends hybrid palliation to all neonates with HLHS; that is, proponents of the Norwood alternative approach suggest that hybrid palliation is a substitute for Norwood-based palliation. Although only a few centers worldwide have adopted this "hybrid-first" approach, these dedicated centers have demonstrated promising outcomes after hybrid palliation as a primary strategy for patients with HLHS. For example, the Giessen group reported an overall survival of $82 \%$ at 1 year, $78 \%$ at 5 years, and $75 \%$ at 10 years after adopting hybrid palliation as their primary strategy. ${ }^{18}$ Similarly, a team from Columbus, Ohio reported an initial overall survival of $82 \%$ over 5 years. Follow-up studies from these 2 centers have reported a combined operative mortality for stage 1 and CS2 of $9.4 \%$ and $8 \%$, respectively. ${ }^{7,18}$ In addition, the Toronto group reported a $6 \%$ mortality after CS2. ${ }^{14}$

In comparison, results of the Single Ventricle Reconstruction (SVR) Trial showed a 3-year transplantation-free survival of $67 \%$ after Norwood with right ventricle to pulmonary artery conduit and $61 \%$ after Norwood-BT. ${ }^{2}$ In addition, a 20-center review comparing hybrid and Norwood survival, showed a 4-year survival after hybrid closer to $61 \%{ }^{29}$ Although intent was not specified for these patients, the hybrid recipients were propensity matched to share similar characteristics as the Norwood patients. These results are similar to those reported by Japanese studies demonstrating an overall 5-year survival of 54\% after hybrid palliation. Of note, Japanese centers use hybrid palliation as their primary treatment strategy more frequently than centers in the United States or Europe, favoring the technique for both high-risk and standard-risk patients. ${ }^{40}$ Approximately $62 \%$ of centers use bilateral PA banding (with or without ductal stenting) as their only stage 1 palliation strategy, with $80 \%$ of centers using hybrid strategies in $>50 \%$ of stage 1 palliation cases. As such, these data need to be interpreted in the context of a heterogeneous patient population. ${ }^{40}$

\section{Hybrid Strategies for High-Risk Patients}

The terms "salvage procedure," "deferred Norwood, "rapid 2-stage Norwood," and "bridge to Norwood" have

TABLE 1. Hybrid palliative strategies

\begin{tabular}{|c|c|}
\hline Palliative strategy & Description \\
\hline Norwood alternative & $\begin{array}{l}\text { Conventional hybrid palliation as a stage } 1 \text { procedure, which includes bilateral pulmonary artery banding. } \\
\text { Management of the atrial septum may be performed at the initial procedure or in a subsequent procedure. Ductal } \\
\text { patency is maintained through long-term administration of prostaglandin or by placement of a ductal stent at the } \\
\text { time of the initial procedure or in a subsequent procedure. The second planned procedure is a comprehensive stage- } \\
2 \text { procedure which includes arch reconstruction and bidirectional cavopulmonary shunt. }\end{array}$ \\
\hline Salvage procedure & Procedure to stabilize hemodynamically unstable patients who are otherwise unsuitable for the Norwood operation. \\
\hline Deferred Norwood & $\begin{array}{l}\text { Strategy to utilize the hybrid approach to intentionally defer the Norwood operation for weeks to months. A Norwood } \\
\text { is the second planned procedure. }\end{array}$ \\
\hline Pretransplantation palliation & $\begin{array}{l}\text { Strategy to utilize bilateral pulmonary artery banding to improve hemodynamic stability while awaiting a suitable } \\
\text { organ for transplantation. }\end{array}$ \\
\hline $\begin{array}{l}\text { Univentricular-biventricular } \\
\text { decision deferral }\end{array}$ & $\begin{array}{l}\text { Strategy to promote growth of left ventricular structures to increase probability of achieving a biventricular repair } \\
\text { typically with deliberate maintenance of a restrictive atrial septum. }\end{array}$ \\
\hline
\end{tabular}


been used to describe the hybrid approach as a strategy for high-risk patients. There is conceptual overlap among these strategies, making it difficult to tease out the specific differences. For example, each strategy can maintain ductal patency via either stenting or continuous prostaglandin infusion and may include atrial septostomy. In addition, each strategy lends itself to a number of secondary surgical approaches, including delayed Norwood, cardiac transplantation, or CS2. However, despite the overlap, these strategies have important differentiating properties.

Salvage procedure. For patients with severe hemodynamic instability, hybrid palliation can serve as an initial stabilizing strategy. Salvage hybrids are generally considered a "last ditch" surgical option, are commonly used as an emergent intervention for rapidly deteriorating patients, many of whom have multisystem organ failure and are considered unfit for a Norwood procedure.

Outcomes reporting hybrid use as a true salvage strategy are limited; however, a few studies describe hybrid palliation in critically ill neonates. The Great Ormond Street group describes 17 high-risk neonates treated with the intent for a rapid 2-stage Norwood. Among these patients, 12 survived to Norwood, and the overall 1-year mortality was $\sim 53 \%{ }^{42}$ In a similar series of 9 critically ill neonates with a planned "bridge to Norwood" strategy, 8 patients survived to a Norwood after initial PA banding, even though 7 of them required extracorporeal membrane oxygen support postoperatively. ${ }^{43}$ In a study from Children's Medical Center in Dallas, Texas evaluating 24 high-risk neonates with end-organ dysfunction (2007-2011), 63\% survived to Norwood, CS2, or primary cardiac transplantation after hybrid palliation. ${ }^{44}$

Deferred Norwood. The difference between a salvage procedure and a deferred Norwood approach is based largely on intent. In both instances, all available posthybrid strategies may be considered. As with a salvage procedure, a deferred Norwood approach is commonly used for neonates who are considered high-risk Norwood candidates. In contrast to a salvage hybrid, a deferred Norwood strategy has been described as an institutional preference on an elective basis for patients who are otherwise satisfactory candidates for a primary Norwood procedure. ${ }^{40}$ Furthermore, although not all children end up undergoing a Norwood, by definition, a deferred Norwood strategy is done with the intent to perform a subsequent Norwood. ${ }^{41}$ Because a Norwood procedure is anticipated in infancy, ductal patency is typically maintained with prostaglandin infusion, and ductal stenting is not performed, to simplify the planned Norwood procedure.

In reports describing intentional deferred Norwood strategies, the time from hybrid stage 1 to Norwood ranged between 7 days and 46 days (Table 2). Japan has the largest published series using a deferred Norwood approach. Among the 256 neonates who underwent bilateral PA banding, 194 underwent a Norwood in rapid succession, 27 underwent CS2, 34 patients died before a subsequent operation, and 1 patient survived without intervention. ${ }^{40}$ Although the authors did not report the survival differences between deferred Norwood and hybrid palliation with CS2, $34 \%$ of neonates died after deferred Norwood, compared with $30 \%$ after CS2. Notably, all patients who eventually underwent cardiac transplantation or conversion to biventricular repair were excluded from the analysis. ${ }^{40}$

Despite being a novel approach requiring longer-term follow-up, the theory behind the deferred Norwood strategy is conceptually intuitive. As such, this approach will likely continue to expand as an option for stage 1 palliation.

Low birth weight. Low birth weight is among the most important predictors for poor outcomes after stage 1 palliation, with most literature suggesting decreased survival after Norwood in neonates weighing $<2.5 \mathrm{~kg}^{28,29,50,51}$ Consequently, hybrid stage 1 palliation has been adopted as a strategy for use in low birth weight neonates. Early reports are promising, demonstrating a threshold for improved survival after hybrid strategies versus Norwood procedures for birth weight 2.0 to $2.5 \mathrm{~kg} .{ }^{18,29,52}$ It is reasonable for centers with hybrid capabilities, irrespective of their Norwood outcomes, to pursue stage-1 hybrid palliation as an initial strategy for low birth weight neonates.

\section{Pretransplantation Palliation}

Hybrid strategies can be used to stabilize hemodynamics and control PBF in neonates with single-ventricle physiology listed for heart transplantation while awaiting a suitable organ. These patients commonly have severely compromised ventricular or tricuspid valve function, precluding Norwood consideration. Alternatively, the family's preference may be to pursue primary transplantation rather than a single-ventricle palliation strategy in a patient who might otherwise be a favorable Norwood candidate. ${ }^{41}$ Neonates who undergo hybrid palliation with a pretransplantation intent may occasionally undergo an alternative treatment (ie, survival to CS2). Despite being among the first indications described for hybrid palliation, ${ }^{5}$ the successful results using a hybrid approach as a pretransplantation palliation strategy have not yet been quantified.

\section{Univentricular-Biventricular Decision Deferral}

Hybrid palliation has been used by some centers to delay the decision between single-ventricle and biventricular repair in neonates with borderline left heart structures. Neonates with small left-sided heart structures approaching a $z$-score of -4 represent a particularly challenging group of patients with respect to selection of the optimal initial palliation strategy. ${ }^{53}$ For these patients, an erroneous decision to pursue a biventricular repair can result in early cardiac failure. Conversely, a Norwood procedure can be undertaken in patients with borderline left heart structures in whom a 
TABLE 2. Published reports of centers using a deferred-Norwood strategy

\begin{tabular}{|c|c|c|c|c|c|c|}
\hline Study & Center & $\begin{array}{c}\text { Number of } \\
\text { patients }\end{array}$ & $\begin{array}{l}\text { High-risk } \\
\text { vs routine }\end{array}$ & $\begin{array}{c}\text { Method of } \\
\text { ductal patency: } \\
\text { PGE vs stent }\end{array}$ & $\begin{array}{c}\text { Time to } \\
\text { Norwood/age }\end{array}$ & $\begin{array}{c}\text { Survival to } \\
\text { SCPC, \% }\end{array}$ \\
\hline Sakamoto, $2011^{45}$ & Nagano, Japan & 11 & Routine & PGE & $1-2 \mathrm{mo}$ & $100 \%$ \\
\hline Gomide et al, $2013^{42}$ & London (GOSH) & 12 & High-risk & PGE & $8 \mathrm{~d} / 38 \mathrm{~d}$ & $83 \%$ \\
\hline Guleserian et al, $2013^{44}$ & Dallas & 7 & High-risk & Stent/PGE & $7 \mathrm{~d}$ & $86 \%$ \\
\hline Davies et al, $2015^{15}$ & Delaware & 14 & High-risk & Stent (8) PGE (6) & $25 \mathrm{~d} / 28 \mathrm{~d}$ & $72 \%$ \\
\hline Murphy, $2015^{46}$ & London (Evelina) & 11 & High-risk & Stent & N/A & $100 \%$ \\
\hline Nassar, $2015^{47}$ & London (Evelina) & 17 & High-risk & Stent & N/A & $14 / 17$ \\
\hline Dodge-Khatami, $2015^{48}$ & Mississippi & 8 & High-risk & PGE & $14 \mathrm{~d}$ & $63 \%$ \\
\hline Hirata et al, $2018^{40}$ & Japan (national database) & 194 & All patients & Stent/PGE & $46 \mathrm{~d}$ & $110 / 194$ \\
\hline Schulz, $2020^{49}$ & Berlin & 14 & High-risk & Stent/PGE & Age $56 \mathrm{~d}$ & $92 \%$ \\
\hline
\end{tabular}

PGE, Prostaglandin infusion; $S C P C$, superior cavopulmonary connection; GOSH, Great Ormand Street Hospital.

biventricular repair was feasible, albeit with the potential for a subsequent 2-ventricle repair. ${ }^{53}$ The concept of ventricular rehabilitation to promote left ventricular growth through maintenance of a mildly restrictive atrial septal defect has been proposed to improve the probability of successful biventricular repair.

The technical details of bilateral PA banding and ductal stenting for left ventricular rehabilitation are the same as in a standard hybrid procedure. The important difference is that the atrial septal defect is intentionally left more restrictive than in other strategies, to force increased blood flow through the mitral valve into the diminutive left ventricle. Early results among centers attempting biventricular repair after initial hybrid palliation are promising; the Giessen group reported successful biventricular repair for 67 of 69 patients with borderline left heart structures. ${ }^{18}$

\section{CONCLUSIONS}

Initially hailed as a panacea when first introduced, by allowing neonates to avoid CPB and altered cerebral perfusion during arch reconstruction, the hybrid procedure for singleventricle palliation was met with great enthusiasm. However, hybrid outcomes have not attained the hoped-for clear superiority as an alternative to the Norwood strategy. Interestingly, although there are some data to suggest that patients treated with hybrid palliation have similar brain magnetic resonance imaging findings as age-matched controls, the data on delaying CPB and DHCA remain inconclusive. Most centers do not routinely use hybrid strategies as an alternative to the Norwood strategy, although high-volume hybrid centers report favorable outcomes.

Like many innovations, the hybrid concept has found a niche in several specific clinical situations. Surgeons have devised creative applications for the strategy, including salvage, pre-transplant palliation, and univentricularbiventricular decision deferral. Additionally, emerging data suggest that low birth weight infants may gain significant benefit from hybrid palliation. Hybrid strategies have evolved into a set of versatile management options that can be adapted to a wide variety of clinical situations for patients of varying clinical acuity. It seems certain that hybrid utilization will continue to expand within these niches, providing an important resource for clinicians in the treatment of patients with HLHS. As hybrid use grows, focusing on standardized terminology regarding palliative intent and risk stratification will provide more robust data, leading to better informed clinical decision making, and ultimately optimized outcomes.

\section{Conflict of Interest Statement}

The authors reported no conflicts of interest.

The Journal policy requires editors and reviewers to disclose conflicts of interest and to decline handling or reviewing manuscripts for which they may have a conflict of interest. The editors and reviewers of this article have no conflicts of interest.

\section{References}

1. Norwood WI, Lang P, Casteneda AR, Campbell DN. Experience with operations for hypoplastic left heart syndrome. J Thorac Cardiovasc Surg. 1981;82:511-9.

2. Newburger JW, Sleeper LA, Frommelt PC, Pearson GD, Mahle WT, Chen S, et al. Transplantation-free survival and interventions at 3 years in the single ventricle reconstruction trial. Circulation. 2014;129:2013-20.

3. Gibbs JL, Wren C, Watterson KG, Hunter S, Hamilton JR. Stenting of the arterial duct combined with banding of the pulmonary arteries and atrial septectomy or septostomy: a new approach to palliation for the hypoplastic left heart syndrome. Br Heart J. 1993;69:551-5.

4. Norwood WI, Lang P, Hansen DD. Physiologic repair of aortic atresiahypoplastic left heart syndrome. N Engl J Med. 1983;308:23-6.

5. Ruiz CE, Gamra H, Zhang HP, García EJ, Boucek MM. Brief report: stenting of the ductus arteriosus as a bridge to cardiac transplantation in infants with the hypoplastic left-heart syndrome. N Engl J Med. 1993;328:1605-8.

6. Gibbs JL, Rothman MT, Rees MR, Parsons JM, Blackburn ME, Ruiz CE. Stenting of the arterial duct: a new approach to palliation for pulmonary atresia. $\mathrm{Br}$ Heart J. 1992;67:240-5.

7. Galantowicz M, Yates AR. Improved outcomes with the comprehensive stage 2 procedure after an initial hybrid stage 1. J Thorac Cardiovasc Surg. 2016;151: 424-9. 
8. Schranz D, Bauer A, Reich B, Steinbrenner B, Recla S, Schmidt D, et al. Fifteenyear single center experience with the "Giessen Hybrid" approach for hypoplastic left heart and variants: current strategies and outcomes. Pediatr Cardiol. 2015; 36:365-73.

9. Kobayashi D, Natarajan G, Turner DR, Forbes TJ, Delius RE, Walters HL, et al. Effect of hybrid stage 1 procedure on ventricular function in infants with hypoplastic left heart syndrome. Cardiol Young. 2016;26:867-75.

10. Newburger JW, Sleeper LA, Gaynor JW, Hollenbeck-Pringle D, Frommelt PC, Li JS, et al. Transplant-free survival and interventions at 6 years in the SVR trial. Circulation. 2018;137:2246-53.

11. Yerebakan C, Valeske K, Elmontaser H, Yörüker U, Mueller M, Thul J, et al. Hybrid therapy for hypoplastic left heart syndrome: Myth, alternative, or standard? J Thorac Cardiovasc Surg. 2016;151:1112-21, 1123.e1-5.

12. Cua CL, McConnell PI, Meza JM, Hill KD, Zhang S, Hersey D, et al. Hybrid palliation: outcomes after the comprehensive stage 2 procedure. Ann Thorac Surg. 2018;105:1455-60.

13. Jacobs JP, Mayer JE Jr, Mavroudis C, O'Brien SM, Austin EH III, Pasquali SK, et al. The Society of Thoracic Surgeons congenital heart surgery database: 2017 update on outcomes and quality. Ann Thorac Surg. 2017;103: 699-709.

14. Baba K, Kotani Y, Chetan D, Chaturvedi RR, Lee KJ, Benson LN, et al. Hybrid versus Norwood strategies for single-ventricle palliation. Circulation. 2012;126: S123-31.

15. Davies RR, Radtke W, Bhat MA, Baffa JM, Woodford E, Pizarro C. Hybrid palliation for critical systemic outflow obstruction: neither rapid stage 1 Norwood nor comprehensive stage 2 mitigate consequences of early risk factors. J Thorac Cardiovasc Surg. 2015;149:182-91.

16. Davies RR, Radtke WA, Klenk D, Pizarro C. Bilateral pulmonary arterial banding results in an increased need for subsequent pulmonary artery interventions. $J$ Thorac Cardiovasc Surg. 2014;147:706-12.

17. Rahkonen O, Chaturvedi RR, Benson L, Honjo O, Caldarone CA, Lee KJ. Pulmonary artery stenosis in hybrid single-ventricle palliation: high incidence of left pulmonary artery intervention. J Thorac Cardiovasc Surg. 2015;149:1102-10.e2.

18. Yörüker U, Akintürk H. Giessen procedure as comprehensive stage II palliation with aortic arch reconstruction after hybrid bilateral pulmonary artery banding and ductal stenting for hypoplastic left heart syndrome. Semin Thorac Cardiovasc Surg Pediatr Card Surg Annu. 2018;21:19-27.

19. Latus H, Nassar MS, Wong J, Hachmann P, Bellsham-Revell H, Hussain T, et al. Ventricular function and vascular dimensions after Norwood and hybrid palliation of hypoplastic left heart syndrome. Heart. 2018;104:244-52.

20. Dave H, Rosser B, Knirsch W, Hübler M, Prêtre R, Kretschmar O. Hybrid approach for hypoplastic left heart syndrome and its variants: the fate of the pulmonary arteries. Eur J Cardiothorac Surg. 2014;46:14-9.

21. Michel-Behnke I, Akintuerk H, Marquardt I, Mueller M, Thul J, Bauer J, et al. Stenting of the ductus arteriosus and banding of the pulmonary arteries: basis for various surgical strategies in newborns with multiple left heart obstructive lesions. Heart. 2003;89:645-50.

22. Pizarro C, Murdison KA. Off pump palliation for hypoplastic left heart syndrome: surgical approach. Semin Thorac Cardiovasc Surg Pediatr Card Surg Апnи. 2005;66-71.

23. Stoica SC, Philips AB, Egan M, Rodeman R, Chisolm J, Hill S, et al. The retrograde aortic arch in the hybrid approach to hypoplastic left heart syndrome. Ann Thorac Surg. 2009:88:1939-46; discussion 1946-7.

24. Caldarone CA, Benson LN, Holtby H, Van Arsdell GS. Main pulmonary artery to innominate artery shunt during hybrid palliation of hypoplastic left heart syndrome. J Thorac Cardiovasc Surg. 2005;130:e1-2.

25. Baba K, Honjo O, Chaturvedi R, Lee KJ, Van Arsdell G, Caldarone CA, et al. "Reverse Blalock-Taussig shunt": application in single ventricle hybrid palliation. J Thorac Cardiovasc Surg. 2013;146:352-7.

26. Austin EH III. Management of retrograde aortic arch malperfusion after hybrid stage I palliation: good save. Learn anything? J Thorac Cardiovasc Surg. 2015;150:e89-90.

27. Feinstein JA, Benson DW, Dubin AM, Cohen MS, Maxey DM, Mahle WT, et al. Hypoplastic left heart syndrome: current considerations and expectations. J Am Coll Cardiol. 2012;59:S1-42.

28. Ohye RG, Sleeper LA, Mahony L, Newburger JW, Pearson GD, Lu M, et al. Comparison of shunt types in the Norwood procedure for single-ventricle lesions. N Engl J Med. 2010;362:1980-92.

29. Wilder TJ, McCrindle BW, Hickey EJ, Ziemer G, Tchervenkov CI, Jacobs ML, et al. Is a hybrid strategy a lower-risk alternative to stage 1 Norwood operation? J Thorac Cardiovasc Surg. 2017;153:163-72.e6.
30. DeCampli WM, Tsai FW, Argueta-Morales IR, Smith C, Munro HM. The effect of epinephrine on coronary flow in the setting of a systemic-to-pulmonary artery shunt. World J Pediatr Congenit Heart Surg. 2013;4:373-9.

31. Li J, Zhang G, Benson L, Holtby H, Cai S, Humpl T, et al. Comparison of the profiles of postoperative systemic hemodynamics and oxygen transport in neonates after the hybrid or the Norwood procedure: a pilot study. Circulation 2007;116:I179-87.

32. Licht DJ, Shera DM, Clancy RR, Wernovsky G, Montenegro LM, Nicolson SC, et al. Brain maturation is delayed in infants with complex congenital heart defects. J Thorac Cardiovasc Surg. 2009;137:529-36; discussion 536-7.

33. Limperopoulos C, Tworetzky W, McElhinney DB, Newburger JW, Brown DW Robertson RL Jr, et al. Brain volume and metabolism in fetuses with congenital heart disease: evaluation with quantitative magnetic resonance imaging and spectroscopy. Circulation. 2010;121:26-33.

34. Back SA, Gan X, Li Y, Rosenberg PA, Volpe JJ. Maturation-dependent vulnerability of oligodendrocytes to oxidative stress-induced death caused by glutathione depletion. J Neurosci. 1998;18:6241-53.

35. Beca J, Gunn JK, Coleman L, Hope A, Reed PW, Hunt RW, et al. New white matter brain injury after infant heart surgery is associated with diagnostic group and the use of circulatory arrest. Circulation. 2013;127:971-9.

36. Knirsch W, Mayer KN, Scheer I, Tuura R, Schranz D, Hahn A, et al. Structural cerebral abnormalities and neurodevelopmental status in single ventricle congenital heart disease before Fontan procedure. Eur J Cardiothorac Surg. 2017;51: 740-6.

37. Knirsch W, Heye KN, Tuura RO, Hahn A, Wetterling K, Latal B, et al. Smaller brain volumes at two years of age in patients with hypoplastic left heart syndrome-impact of surgical approach. Int J Cardiol. 2019;291:42-4.

38. Durán-Carabali LE, Arcego DM, Odorcyk FK, Reichert L, Cordeiro JL, Sanches EF, et al. Prenatal and early postnatal environmental enrichmen reduce acute cell death and prevent neurodevelopment and memory impairments in rats submitted to neonatal hypoxia ischemia. Mol Neurobiol. 2018; $55: 3627-41$.

39. Karamlou T, Overman D, Hill KD, Wallace A, Pasquali SK, Jacobs JP, et al Stage 1 hybrid palliation for hypoplastic left heart syndrome-assessment of contemporary patterns of use: an analysis of the Society of Thoracic Surgeons congenital heart surgery database. J Thorac Cardiovasc Surg. 2015;149: 195-201, 202.e1.

40. Hirata Y, Miyata H, Hirahara N, Murakami A, Kado H, Sakamoto K, et al. Long term results of bilateral pulmonary artery banding versus primary Norwood procedure. Pediatr Cardiol. 2018;39:111-9.

41. Haller C, Caldarone CA. The evolution of therapeutic strategies: Niche apportionment for hybrid palliation. Ann Thorac Surg. 2018;106: $1873-80$.

42. Gomide M, Furci B, Mimic B, Brown KL, Hsia TY, Yates R, et al. Rapid 2-stage Norwood I for high-risk hypoplastic left heart syndrome and variants. $J$ Thorac Cardiovasc Surg. 2013;146:1146-51; discussion 1151-2.

43. Greenleaf CE, Urencio JM, Salazar JD, Dodge-Khatami A. Hypoplastic left heart syndrome: current perspectives. Transl Pediatr. 2016;5:142-7.

44. Guleserian KJ, Barker GM, Sharma MS, Macaluso J, Huang R, Nugent AW, et al. Bilateral pulmonary artery banding for resuscitation in high-risk, single-ventricle neonates and infants: a single-center experience. J Thorac Cardiovasc Surg. 2013;145:206-13; discussion 213-4.

45. Sakamoto T, Harada Y, Kosaka Y, Umezu K, Yasukochi S, Takigiku K, et al. Second-stage palliation after bilateral pulmonary artery bands for HLHS and its variants - Which is better, modified Norwood or Norwood plus bidirectional Glenn? World J Pediatr Congenit Heart Surg. 2011;2:558-65.

46. Murphy MO, Bellsham-Revell H, Morgan GJ, Krasemann T, Rosenthal E, Quereshi SA, et al. Hybrid procedure for neonates with hypoplastic left heart syndrome at high-risk for Norwood: midterm outcomes. Ann Thorac Surg. 2015; 100:2286-92.

47. Nassar MS, Narayan SA, Nyman A, Salih C, Austin CB, Anderson D, et al. Second stage after initial hybrid palliation for hypoplastic left heart syndrome: arterial or venous shunt. J Thorac Cardiovasc Surg. 2015;150:350-7.

48. Dodge-Khatami A, Chancellor WZ, Gupta B, Seals SR, Ebeid MR, Bativala SP, et al. Achieving benchmark results for neonatal palliation of hypoplastic left heart syndrome and related anomalies in an emerging program. World J Pediatr Congenit Heart Surg. 2015;6:393-400.

49. Schulz A, Sinzobahamvya N, Cho M, Bottcher W, Miera O, Redlin M, et al Bilateral pulmonary artery banding before Norwood procedure: survival of high-risk patients. Thorac Cardiovasc Surg. 2020;68:30-7. 
50. Hickey EJ, Nosikova Y, Zhang H, Caldarone CA, Benson L, Redington A, et al. Very low-birth-weight infants with congenital cardiac lesions: is there merit in delaying intervention to permit growth and maturation? J Thorac Cardiovasc Surg. 2012;143:126-36, 136.e1.

51. Wilder TJ, McCrindle BW, Phillips AB, Blackstone EH, Rajeswaran J, Williams WG, et al. Survival and right ventricular performance for matched children after stage-1 Norwood: modified Blalock-Taussig shunt versus rightventricle-to-pulmonary-artery conduit. J Thorac Cardiovasc Surg. 2015;150: $1440-50$.
52. Stasik CN, Gelehrter S, Goldberg CS, Bove EL, Devaney EJ, Ohye RG. Current outcomes and risk factors for the Norwood procedure. J Thorac Cardiovasc Surg. 2006;131:412-7.

53. Emani SM, McElhinney DB, Tworetzky W, Myers PO, Schroeder B, Zurakowski D, et al. Staged left ventricular recruitment after single-ventricle palliation in patients with borderline left heart hypoplasia. J Am Coll Cardiol. 2012;60:1966-74

Key Words: hypoplastic left heart syndrome, hybrid stage 1 